\title{
Extensively drug-resistant tuberculosis hovers threateningly at Australia's door
}

\section{Tony Kirby explains why we should provide full care to all people arriving with resistant tuberculosis}

t was hoped that extensively drug-resistant tuberculosis (XDR-TB) might never arrive on Australia's shores. But new cases raise the spectre of death for patients, transmission to others and large costs for Australian taxpayers. Papua New Guinea (PNG) national Catherina Abraham, aged 20 years, "made it" to Australia and hit the headlines in October 2012 because she had been diagnosed with XDR-TB. ${ }^{1}$ After almost a year in an isolation ward at Cairns Base Hospital, she died on 8 March 2013. Her treatment cost Queensland Health about $\$ 500000$ and would have cost \$1 million had she lived to complete it. Now another PNG national has been diagnosed with XDR-TB in Australia. In the preceding 8 years, only two other XDR-TB cases were recorded in Australia. ${ }^{2}$

According to Queensland Health, the most recently diagnosed patient came through the Torres Strait, was referred to Cairns Base Hospital and was transferred to PNG health services before the laboratory diagnosis of XDR-TB was made. He or she is currently in Daru Hospital (in PNG's Western Province, the closest to Cape York). Although TB treatment is meant to be free for patients in PNG, potential exposure to other patients, the cost of sourcing active drugs, and the complexity and length of XDR-TB treatment mean that this patient is at significant risk of dying. A recent television exposé of Daru Hospital showed numerous patients with XDR-TB and multi-drug resistant TB (MDR-TB) mixing together and leaving their isolation wards, resulting in the risk of drugresistant TB spreading through the community. ${ }^{1}$ Experts believe Abraham would have died within 1 month had she not reached Cairns and also predict that Australia could see its own outbreak of XDR-TB within 5 years. ${ }^{1}$

In comparison, 24 patients have been diagnosed with XDR-TB in the United Kingdom since 1995, six of whom were diagnosed in 2011. ${ }^{3}$ Patients with XDR-TB and the stillchallenging MDR-TB in the UK are largely migrants from Eastern Europe, Africa and Asia. Last year, the UK government began requiring new entrants from TB-prevalent nations to have a chest $x$-ray with them on arrival to be granted a visa to enter the UK. ${ }^{3}$ Yet, owing to the UK's porous air and sea borders and its accessibility and proximity to Europe, it is much more vulnerable than Australia to receiving patients with MDR-TB and XDR-TB. According to the UK's Health Protection Agency, screening new entrants for latent TB would also be desirable. However, Australia is unlikely to enact a similar policy since it would produce many positive results for latent infection without identifying which patients would progress to active or drug-resistant disease (Justin Waring, Chair of the National Tuberculosis Advisory

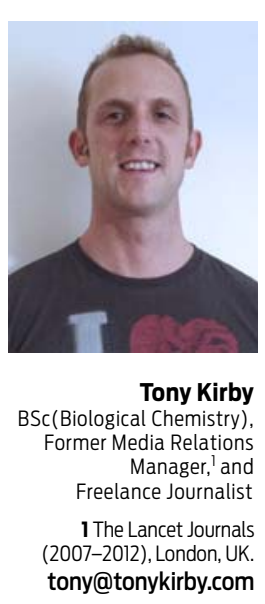

doi: 10.5694/mjal3.10178

Experts ... predict that Australia could see its own outbreak of XDR-TB within 5 years

Online first 20/03/13
Committee, personal communication). So apart from the Qld-PNG border, it is difficult to predict where other XDR-TB or MDR-TB cases may appear in Australia, since migrants with latent infection can reside in any Australian city or region.

In Australia, significant resources can, at present, be directed at patients with XDR-TB. Yet in PNG, all forms of TB compete for resources with a catalogue of other health and social problems, including high rates of diarrhoeal illness, pneumonia, HIV (many patients with HIV are co-infected with TB), malaria, maternal mortality, and widespread and crippling poverty.

The strategic plan for control of tuberculosis in Australia: 2011-2015 highlights the need to increase engagement with regional partners in TB control, particularly PNG's Western Province. ${ }^{5}$ The plan also stresses that Australia's workforce with TB expertise is diminishing, while its workload is increasing because of increasing numbers of patients from TB-prevalent countries and increasing complexity of cases, including drug resistance. TB is also becoming increasingly unfamiliar on the overcrowded curriculum for Australia's medical students. ${ }^{5}$ Going forward, continued TB education and training for general practitioners will be vital to enable rapid diagnosis of active $\mathrm{TB}$ (wherever it may occur), minimise transmission, and enable use of the latest technology to identify and treat patients with drug-resistant TB. ${ }^{2}$

Well coordinated TB management programs and general health care provision for people of Western Province must be urgently expanded to avoid increases in incidence of MDR-TB and XDR-TB and reduce the risk of more patients arriving in Australia. But patients who receive inadequate treatment in poor nations such as PNG, and patients who are unknowingly infected, will inevitably reach the Torres Strait or Australia's mainland. Thus, conscious of Australia's position as one of the world's richest countries, TB experts agree that all patients with TB who present to health services in Australia should have free and equal access to TB care - from diagnosis to completion of treatment - irrespective of their legal status or demographic characteristics. ${ }^{6}$

Competing interests: No relevant disclosures.

Provenance: Commissioned; not externally peer reviewed.

1 Rise of the superbugs. Four Corners [television program]. Australian Broadcasting Corporation, 2012; 29 Oct. http:// www.abc.net.au/4corners/stories/2012/10/25/3618608.htm (accessed Jan 2012).

2 Johnson PDR. Extensively resistant tuberculosis in the lands Down Under [editorial]. Med J Aust 2011; 194:565-566. 3 Health Protection Agency (UK). Tuberculosis in the UK: 2012 report. http://www.hpa.org.uk/webc/HPAwebFile/ HPAweb_C/1317134913404 (accessed Jan 2013).

4 McBryde E. Evaluation of risks of tuberculosis in Western Province Papua New Guinea. http://www.ausaid.gov.au/ countries/pacific/png/Documents/png-tb-evaluation-of-risk.pdf (accessed Feb 2012).

5 National Tuberculosis Advisory Committee. The strategic plan for control of tuberculosis in Australia: 2011-2015. Commun Dis Intell 2012; 36: E286-E293.

6 Reynolds PN, Turnidge JD, Gottlieb T, Moore MJ; Thoracic Society of Australia and New Zealand; Australian Society for Microbiology; Australasian Society for Infectious Diseases; Public Health Association of Australia. Cross-border patients with tuberculosis [position statement]. Med J Aust 2011; 195: 523-524. 


\section{Extensively drug-resistant tuberculosis hovers threateningly at Australia's door}

\section{Tony Kirby explains why we should provide full care to all people arriving with resistant tuberculosis}

t was hoped that extensively drug-resistant tuberculosis (XDR-TB) might never arrive on Australia's shores. But new cases raise the spectre of death for patients, transmission to others and large costs for Australian taxpayers. Papua New Guinea (PNG) national Catherina Abraham, aged 20 years, "made it" to Australia and hit the headlines in October 2012 because she had been diagnosed with XDR-TB. ${ }^{1}$ After almost a year in an isolation ward at Cairns Base Hospital, she died on 8 March 2013. Her treatment cost Queensland Health about $\$ 500000$ and would have cost \$1 million had she lived to complete it. Now another PNG national has been diagnosed with XDR-TB in Australia. In the preceding 8 years, only two other XDR-TB cases were recorded in Australia. ${ }^{2}$

According to Queensland Health, the most recently diagnosed patient came through the Torres Strait, was referred to Cairns Base Hospital and was transferred to PNG health services before the laboratory diagnosis of XDR-TB was made. He or she is currently in Daru Hospital (in PNG's Western Province, the closest to Cape York). Although TB treatment is meant to be free for patients in PNG, potential exposure to other patients, the cost of sourcing active drugs, and the complexity and length of XDR-TB treatment mean that this patient is at significant risk of dying. A recent television exposé of Daru Hospital showed numerous patients with XDR-TB and multi-drug resistant TB (MDR-TB) mixing together and leaving their isolation wards, resulting in the risk of drugresistant TB spreading through the community. ${ }^{1}$ Experts believe Abraham would have died within 1 month had she not reached Cairns and also predict that Australia could see its own outbreak of XDR-TB within 5 years. ${ }^{1}$

In comparison, 24 patients have been diagnosed with XDR-TB in the United Kingdom since 1995, six of whom were diagnosed in 2011. ${ }^{3}$ Patients with XDR-TB and the stillchallenging MDR-TB in the UK are largely migrants from Eastern Europe, Africa and Asia. Last year, the UK government began requiring new entrants from TB-prevalent nations to have a chest $x$-ray with them on arrival to be granted a visa to enter the UK. ${ }^{3}$ Yet, owing to the UK's porous air and sea borders and its accessibility and proximity to Europe, it is much more vulnerable than Australia to receiving patients with MDR-TB and XDR-TB. According to the UK's Health Protection Agency, screening new entrants for latent TB would also be desirable. However, Australia is unlikely to enact a similar policy since it would produce many positive results for latent infection without identifying which patients would progress to active or drug-resistant disease (Justin Waring, Chair of the National Tuberculosis Advisory

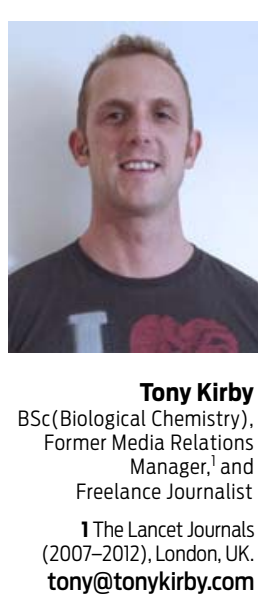

doi: 10.5694/mjal3.10178

Experts ... predict that Australia could see its own outbreak of XDR-TB within 5 years

Online first 20/03/13
Committee, personal communication). So apart from the Qld-PNG border, it is difficult to predict where other XDR-TB or MDR-TB cases may appear in Australia, since migrants with latent infection can reside in any Australian city or region.

In Australia, significant resources can, at present, be directed at patients with XDR-TB. Yet in PNG, all forms of TB compete for resources with a catalogue of other health and social problems, including high rates of diarrhoeal illness, pneumonia, HIV (many patients with HIV are co-infected with TB), malaria, maternal mortality, and widespread and crippling poverty.

The strategic plan for control of tuberculosis in Australia: 2011-2015 highlights the need to increase engagement with regional partners in TB control, particularly PNG's Western Province. ${ }^{5}$ The plan also stresses that Australia's workforce with TB expertise is diminishing, while its workload is increasing because of increasing numbers of patients from TB-prevalent countries and increasing complexity of cases, including drug resistance. TB is also becoming increasingly unfamiliar on the overcrowded curriculum for Australia's medical students. ${ }^{5}$ Going forward, continued TB education and training for general practitioners will be vital to enable rapid diagnosis of active $\mathrm{TB}$ (wherever it may occur), minimise transmission, and enable use of the latest technology to identify and treat patients with drug-resistant TB. ${ }^{2}$

Well coordinated TB management programs and general health care provision for people of Western Province must be urgently expanded to avoid increases in incidence of MDR-TB and XDR-TB and reduce the risk of more patients arriving in Australia. But patients who receive inadequate treatment in poor nations such as PNG, and patients who are unknowingly infected, will inevitably reach the Torres Strait or Australia's mainland. Thus, conscious of Australia's position as one of the world's richest countries, TB experts agree that all patients with TB who present to health services in Australia should have free and equal access to TB care - from diagnosis to completion of treatment - irrespective of their legal status or demographic characteristics. ${ }^{6}$

Competing interests: No relevant disclosures.

Provenance: Commissioned; not externally peer reviewed.

1 Rise of the superbugs. Four Corners [television program]. Australian Broadcasting Corporation, 2012; 29 Oct. http:// www.abc.net.au/4corners/stories/2012/10/25/3618608.htm (accessed Jan 2012).

2 Johnson PDR. Extensively resistant tuberculosis in the lands Down Under [editorial]. Med J Aust 2011; 194:565-566. 3 Health Protection Agency (UK). Tuberculosis in the UK: 2012 report. http://www.hpa.org.uk/webc/HPAwebFile/ HPAweb_C/1317134913404 (accessed Jan 2013).

4 McBryde E. Evaluation of risks of tuberculosis in Western Province Papua New Guinea. http://www.ausaid.gov.au/ countries/pacific/png/Documents/png-tb-evaluation-of-risk.pdf (accessed Feb 2012).

5 National Tuberculosis Advisory Committee. The strategic plan for control of tuberculosis in Australia: 2011-2015. Commun Dis Intell 2012; 36: E286-E293.

6 Reynolds PN, Turnidge JD, Gottlieb T, Moore MJ; Thoracic Society of Australia and New Zealand; Australian Society for Microbiology; Australasian Society for Infectious Diseases; Public Health Association of Australia. Cross-border patients with tuberculosis [position statement]. Med J Aust 2011; 195: 523-524. 